\title{
Decision making styles and the use of heuristics in decision making
}

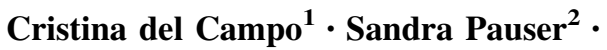 \\ Elisabeth Steiner ${ }^{2} \cdot$ Rudolf Vetschera $^{2}$ (D)
}

(C) The Author(s) 2016. This article is published with open access at Springerlink.com

\begin{abstract}
Simple heuristics can be efficient ways of decision making and literature has shown that they are widely used in actual decision situations. Although many types of heuristics have been found and analyzed, there is only scarce research on factors that lead to the use of a particular heuristic. In the present paper, we describe an experiment to analyze whether the usage of a particular heuristic like recognition or take-the-best depends on individual decision making styles as identified by Scott and Bruce (Educ Psychol Meas 55(5):818-831, 1995). The experiment is based on a choice problem, in which different heuristics are likely to lead to different choices. Analyzing experimental data from two replications of the experiment in two different countries, we find some evidence that decision making styles influence the use of heuristics. However, considerable differences between the two experiments indicate that other, perhaps cultural, factors might also be important.
\end{abstract}

Keywords Heuristics · Decision making styles · Time pressure - Consumer choice $\cdot$ Multivariate statistics

Rudolf Vetschera

rudolf.vetschera@univie.ac.at

Cristina del Campo

campocc@ccee.ucm.es

Sandra Pauser

sandra.pauser@univie.ac.at

Elisabeth Steiner

elisabeth.steiner@univie.ac.at

1 Department of Statistics and OR (Decision Analysis), Universidad Complutense de Madrid, Campus de Somosaguas, 28223 Madrid, Spain

2 Department of Business Adminstration, University of Vienna, Oskar Morgenstern Platz 1, 1090 Vienna, Austria 
JEL Classification $\quad$ M21 · D83 · C91

\section{Introduction}

In many everyday decisions, for example purchasing situations, economic actors often rely on simple heuristics rather than on elaborate calculations (Hauser 2011). In the course of the last decades, literature has identified many different types of heuristics that could be applied in such simple decision situations, like the recognition heuristic (Gigerenzer and Goldstein 2011) or the take-the-best heuristic (Gigerenzer and Goldstein 1996; Newell et al. 2003). To better understand the behavior of economic actors, it thus becomes crucial to find out which heuristic is used under which circumstances. However, empirical literature on heuristics so far has mainly focused on establishing the precise characteristics of each heuristic, e.g. if decision makers really rely on just one single clue (Pohl 2006), or whether clues are used in a compensatory or noncompensatory manner (Pachur et al. 2008). Although this research has significantly contributed to our understanding of how these heuristics actually work, the factors that trigger the use of a particular heuristic have only been scarcely studied in literature to date.

A person makes a decision (and possibly uses a heuristic for decision making) in a certain situation. The use of a heuristic could thus be triggered both by situational factors such as task and context (Payne et al. 1993), and by personal factors. Some situational factors that were studied in the literature include time pressure (Hilbig et al. 2012) or the way in which information on the problem is presented (Bröder and Schiffer 2006). Personal factors include intelligence (Bröder 2003) and some of the Big Five personality factors, in particular neuroticism (Hilbig 2008).

Empirical literature on decision making has not only identified different heuristics that one might use in making decisions, but has also developed classifications of decision making styles, which characterize the different ways of how people approach decision problems. Scott and Bruce (1995) developed a fivedimensional instrument for measuring decision making styles, in which they distinguish between rational, intuitive, spontaneous, dependent and avoidant styles. Although the relationship between those styles and the use of heuristics for decision making seems intuitively plausible, it has to the best of our knowledge not been studied before.

The main aim of this paper is, therefore, to study the relationship between decision making styles and the use of different heuristics. Previous research has already shown that time pressure is an important factor in triggering the use of decision making heuristics. We therefore employ this factor in order to create a situation in which decision makers are more likely to rely on heuristics, and then study the type of heuristics subjects with different decision making styles employ in this situation.

Our approach differs from previous research on heuristics in decision making in that we study the choice of one out of several heuristics, and thus consider several heuristics in parallel. We therefore create a situation in which decision makers need to select among several alternatives, and subjects following a particular heuristic 
will likely choose a particular alternative. In line with current literature, this choice is framed as an everyday choice situation, in which the use of heuristics is likely to occur, rather than an important decision that would trigger elaborate cognitive processes. We furthermore use time pressure as an experimental factor in order to compare a situation in which the use of heuristics is likely to happen as opposed to a situation in which subjects might rely more on cognition. Finally, in order to test the stability of our results, we conducted two identical experiments in different countries (Austria and Spain) having quite different cultures.

The remainder of this paper is structured as follows: In Sect. 2, we review the literature on the use of heuristics and on decision making styles in order to formulate our research questions on the possible relationships between them. Section 3 describes the experiments which we performed and in Sect. 4 the results are presented. Those results are further discussed in Sect. 5, which concludes the paper.

\section{Literature review and research questions}

The main aim of this paper is to find factors that will trigger the use of some particular heuristics in a (consumer) choice situation. We therefore briefly review the empirical literature on heuristics and on possible factors influencing the use of those heuristics, before we finally proceed to formulate our research questions.

\subsection{Heuristics}

In a world of limited knowledge, resources, and time, the concept of rational decision making is not always a suitable model to describe and explain human behavior. Research indicates that individuals, due to a lack of time and commitment, tend to rely on shortcuts when making decisions (Payne et al. 1993). As a consequence, the concept of fast and frugal heuristics has gained attention as an important concept to describe human judgments (Gigerenzer et al. 1999). The term heuristic stems from Greek, meaning to find, and it is used in cognitive psychology as a "useful shortcut, an approximation, or a rule of thumb for searching through a space of possible solutions" (Hoffrage and Reimer 2004, p. 439).

The literature on fast and frugal heuristics pioneered by Gigerenzer et al. (1999) has identified several different types of heuristics that can be used in decision processes. In this paper, we particularly focus on two heuristics from the "adaptive toolbox" proposed by Gigerenzer et al. (1999), which are widely discussed in literature and which can be seen as particularly closely related to consumer decision making (Hauser 2014, p.1692), the recognition heuristic and the take-the-best heuristic. The recognition heuristic has been related to consumer choices in several empirical studies (Marewski et al. 2010; Hauser 2011; Thoma and Williams 2013; Hilbig 2014). Take-the-best is among the most studied heuristics, and since it refers to potentially multiple attributes of alternatives, it is considered a plausible model of boundedly rational decision making (Martignon and Hoffrage 2002). We experimentally study the use of those heuristics in comparison to a more rational, but also 
cognitively more demanding decision process, as well as an affective decision process guided by emotions.

The recognition heuristic as an efficient rule of thumb can be described as a frugal inference strategy relying on only one piece of information, namely the recognition cue (Hilbig and Pohl 2008), and ignoring other information (Hilbig 2014). According to Gigerenzer and Goldstein (2011), if a decision maker has to make a choice between two objects and recognizes one of them, he or she infers that the recognized object has the higher value on a given criterion and thus will prefer it over the unrecognized object. Empirical evidence demonstrates that this one-cue non-compensatory heuristic can be surprisingly accurate (Hilbig 2014), resulting in a remarkably high number of correct inferences by individuals (Borges et al. 1999) and in better predictions regarding consumer behavior than compensatory models (Marewski et al. 2010). Relying on recognition can be useful, particularly considering the fact that recognition lasts long and is easily accessible. While it is not limited to the case of just two alternatives, its application is limited to problems involving only a small number of alternatives (Marewski et al. 2010), and some experiments have shown that alternative compensatory models account better for aggregate data patterns (Hilbig 2014). The recognition heuristic has been widely studied, but has received only mixed support in literature on probabilistic inferences. However, very few studies focus on the application of the recognition heuristic in preferential decision situations such as consumer choice (Hilbig 2014). Marewski et al. (2010) propose that recognition is used to form consideration sets of alternatives, so that unrecognized alternatives are ranked behind recognized alternatives.

The take-the-best heuristic takes into account that decision makers might possess several clues about the objects they have to decide on, but it proposes that decision makers use only one single cue in the decision making process. For example, when estimating the size of a city, such cues could be whether the city has an airport, an opera house, etc. (Reimer and Rieskamp 2007). Decision makers then would assume that the city that has such a facility (while the others do not) is also larger. The takethe-best heuristic tries cues in order of validity, one after the other, and stops at the first cue that discriminates between the objects under consideration (Gigerenzer et al. 1999). Take-the-best is considered to be a fast heuristic due to the fact that it does not require complicated computations and it is frugal because the stopping rule limits the search for cues, sometimes even to just one cue.

Fast and frugal heuristics like recognition or take-the-best still resemble rational theories of decision making in that they apply (although only limited) information on the available alternatives to evaluate the alternatives and ultimately make a choice. Depending on the heuristic, information can be processed in a compensatory or non-compensatory manner. However, humans sometimes approach decision problems also in a very different way and rely on emotions in decision making. Gigerenzer (2001, p. 6-7) points out that "theories of decision making have often neglected emotions, and sometimes even cast them as the very opposite of rationality." Nevertheless, emotions are a crucial factor when being engaged in decisions and can support the process of decision making (Gigerenzer 2001). In this 
context, emotions can be classified as behavioral theories and are sometimes also referred to as affect heuristic (Slovic et al. 2007).

\subsection{Factors influencing the use of heuristics}

Empirical literature has shown that heuristics are not universally used: they are used only by a fraction of subjects, and only in certain situations. For example, Newell et al. (2003) found that roughly one third of subjects were actually using take-thebest. Similarly, in the experiments of Bröder (2000) and Bröder and Schiffer (2006), between 28 and $53 \%$ of the subjects were classified as using take-the-best. Other studies found even lower numbers, for example Glöckner and Bröder (2011) found that less than $10 \%$ of their subjects used recognition, and only about $15 \%$ used take-the-best. Concerning the recognition heuristic, Pachur et al. (2008) found that about half of their subjects used recognition in a strict sense (without incorporating additional information).

This limited extent of actual use of heuristics has led researchers to study factors that could influence the application of heuristics. Gigerenzer and Goldstein (2011) thus noted that decision makers seem to apply different decision strategies, but little is known about the factors that influence their choice. One framework to explain the choice of different approaches to decision making is the effort-accuracy framework by Payne et al. (1993). According to this framework, a decision making strategy is selected by considering the trade-off between the cognitive effort needed to make a decision, and the quality of the decision, since methods leading to better decisions typically also require higher effort. However, since the fast and frugal heuristics we consider here are all characterized by very little cognitive effort, this framework cannot be applied to the choice between these heuristics.

Two types of factors can be distinguished: factors that refer to individual characteristics of the decision maker, and factors related to the decision problem or the environment. Research on individual factors has indicated that intelligence moderates the choice of decision strategies such as heuristics (Bröder 2003). Researchers also studied the impact of the Big Five personality characteristics on the use of heuristics and found that persons high in neuroticism are more likely to use the recognition heuristic (Hilbig 2008). Furthermore, additional knowledge (beyond recognition) a decision maker has about alternatives has some impact on choices (Pohl 2006), although its impact seems to be limited (Hilbig et al. 2009).

The type of environment in which a decision is made has also an impact on the decision making strategy (Bröder 2003). In particular, a high amount of uncertainty present in the environment seems to increase reliance on heuristics like take-the-best (Hogarth and Karelaia 2006; Newell et al. 2003). The choice of strategies also depends on the availability of additional cues, their validity and the cost at which such information can be obtained. If the validity of the primary cue is high, take-thebest is more often used (Newell et al. 2003), while higher validity of other cues reduces its usage (Newell and Fernandez 2006). Some authors also report that the cost of additional information increases the use of heuristics (Newell et al. 2003), while others report that choices can still be better explained by alternative models even if information acquisition has high costs (Ayal and Hochman 2009). 
Another important factor that influences the use of heuristics is time pressure. A positive effect of time pressure on the use of the recognition heuristic was found by Pachur and Hertwig (2006). Furthermore, Hilbig et al. (2012) found that time pressure increases reliance on the recognition heuristic even when violating time constraints does not have a negative impact on the decision maker. It thus seems that the mere presence of time pressure has a strong effect on the choice of a decision strategy. Time pressure was also used as an experimental factor to induce heuristic choice behavior in consumer decision experiments, like for example Langner and Krengel (2013).

Since the presence or absence of time pressure is likely to induce different levels of use of heuristics for the same decision problem, we employ it as an experimental factor in the subsequent empirical study to trigger the use of heuristics in decision making.

\subsection{Decision making styles}

In contrast to factors related to the choice problem, research on individual factors that might trigger the use of heuristics is so far limited. However, decision making behavior in general has been studied more intensively, and different classifications of decision making styles can be found in the literature. Many of them refer to specific settings like shopping situations (Sproles and Kendall 1986). For this paper, we use a more general classification of decision making styles developed by Scott and Bruce (1995). They distinguish five dimensions of a decision making style:

- Rational: This style is characterized by making decisions in a logical and systematic way, or considering various options in terms of a specific goal.

- Intuitive: This style is characterized by relying on intuition and making decisions that "feel right".

- Dependent: This style represents decision makers who tend to consult others before making a decision, and who rely on the assistance and support of others.

- Avoiding: This style is characterized as putting off decisions or making decisions only at the last minute.

- Spontaneous: This style refers to making quick and impulsive decisions.

These five styles represent different dimensions of a decision making process. The instrument of Scott and Bruce (1995) does not classify decision makers uniquely into one style, but assigns each decision maker a score in each dimension indicating how much that decision maker's individual style resembles each of the five prototypical styles.

The instrument developed by Scott and Bruce (1995) has been extensively used in studies on decision making behavior. Among them, and in direct relation with the present paper, Crossley and Highhouse (2005) used a variant of the instrument to classify different approaches applicants use in searching for jobs. Curseu and Schruijer (2012) studied the relationship of decision making styles to actual decision performance and found that subjects scoring high in the rational dimension were less affected by decision biases, and subjects scoring high on the avoiding style 
were more indecisive. Similarly, de Bruin et al. (2007) found a positive relationship between rational decision making style and decision competence. Gettinger et al. (2013) used the instrument to classify users of a decision support system and their preferences for different graphical information representations.

Although many of the items used in the instrument by Scott and Bruce (1995) describe decision making behavior that either reflects the use of heuristics (e.g., "When making decisions, I rely on my instincts", item I1 for the intuitive style), or reflect the avoidance of heuristics (e.g., "My decision making requires careful thought", item R3 of the rational style), to the best of our knowledge the relationship between decision making styles and the use of fast and frugal heuristics has not been studied before. We therefore in the next subsection formulate research questions to explore this relationship. There we also consider time pressure as a problem characteristic that can trigger the use of heuristics in general.

\subsection{Research questions}

The relationship between time pressure and the use of heuristics has been previously studied in literature (Hilbig et al. 2012), but for the sake of completeness, we still formulate it as a research question:

RQ1: Does time pressure increase the use of heuristics in comparison to a rational choice?

Bröder and Schiffer (2006) test the effects of the presence of verbal information on the use of several compensatory (Franklin's Rule, Dawes's Rule) and one noncompensatory (take-the-best) heuristic. They find that cognitive load enhances the usage of take-the-best irrespective of the stimulus format. As take-the-best may be considered the easiest way to reach a decision that is at least partly rational, we expect rational decision makers to switch from a thorough analysis of the problem to a take-the-best heuristic under time pressure.

$R Q 2$ : Do decision makers who score high on the rational dimension apply the take-the-best heuristic rather than other heuristics when they are under time pressure?

Marketing scholars suggest that recognition based decision rules are particularly applicable for purchase decisions regarding frequently purchased product categories (Hauser 2011). Recognition based decision rules can be considered a comparatively easy way to reach a decision, and do not require acquisition of further information on product attributes. Since avoidant decision makers tend to postpone decisions, it is reasonable to assume that they will also try to circumvent the initial pre-decision step of acquiring additional information. Therefore, it can be assumed that avoidant decision makers will make more use of the recognition heuristic than decision makers who score low on the avoidance dimension, and that this relationship will hold both under time pressure and without time pressure. The same might hold for dependent decision makers, since well-known products are also those products which are bought by many other consumers.

$R Q 3:$ Is there a positive relationship between avoidant and/or dependent style and the use of the recognition heuristic? 
Spontaneous decision makers tend to make fast and spontanous decisions, but do not necessarily rely as much on intuition and gut feeling as intuitive decision makers. Thus, they will likely use an approach that is based on some, but only limited information about the alternatives. Their decision making behavior will therefore more likely match the take-the-best heuristic, which bases a decision on factual information about one attribute, rather than, for example, the recognition heuristic, which does not directly consider any attribute of the decision alternative. We also consider it unlikely that spontaneous decision makers will engage in the heavy cognitive processing required to find an objectively best alternative.

RQ4: Is there a positive relationship between the spontaneous style and the use of the take-the-best heuristic?

\section{Experiment}

In order to study the relationship between decision making styles and the use of different heuristics, we performed an experiment in two different countries focusing on the use of selected fast and frugal heuristics in everyday purchase decisions for food products. Participants in a computer-based experiment were asked to choose among five different alternatives of an everyday food product. For this purpose, we selected eggs as a product category as they are known, consumed and purchased on a regular basis by the majority of consumers. On the other hand, consumers might be more involved in egg purchase decisions than in purchase decisions for other comparable everyday foodstuffs due to the extremely intensive systems of production for regular eggs and the growing concern about animal welfare (Mesías et al. 2011).

Employing an experimental between-subjects design, we used presence or absence of time pressure as the manipulated factor. The same choice task was presented in both conditions. Subjects had to make a choice between five types of eggs packaged in different cartons (Fig. 1). Each of the five different stimuli targeted a specific heuristic (or no heuristic). Specifically, two stimuli targeted the take-the-best heuristic and the recognition heuristic, respectively, one was designed to trigger an emotional response, one required high cognitive processing, and the fifth stimulus was a filler product which was not targeted at any specific behavior. The presentation order of the five stimuli within the questionnaire was randomized, ensuring a counterbalanced presentation of all the stimuli.

In the online experiment, participants were asked to put themselves in a situation of purchasing eggs and were requested to choose one option among five different offers. Respondents were randomly assigned to either the time pressure condition or the condition without time pressure. In the condition without time pressure, respondents were not restricted to a time limit while in the former condition, participants were informed that they had to decide on a product within forty seconds calculated from the moment of proceeding to the stimulus material. Comparable time horizons can be found in the literature. Langner and Krengel (2013) applied a time pressure condition of ninety seconds for selecting a cell phone, which is a considerably more complex product, to decrease the amount of cognitive processing 


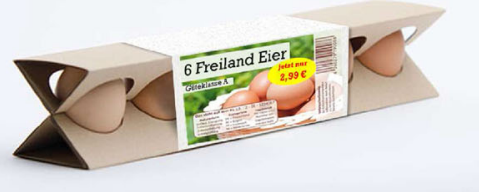

Price: only 2.99 Euro

Raising: free-range

Quality Grade: A

Country of Origin: Austria

Shelf Life: 2 weeks

Quantity: 6 eggs

"Take-the-best" stimulus

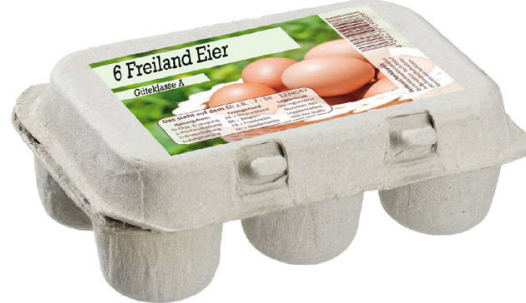

Price: 3.19 Euro

Raising: free-range

Quality Grade: A

Country of Origin: Austria

Shelf Life: 2 weeks

Quantity: 6 eggs

"Recognition" stimulus

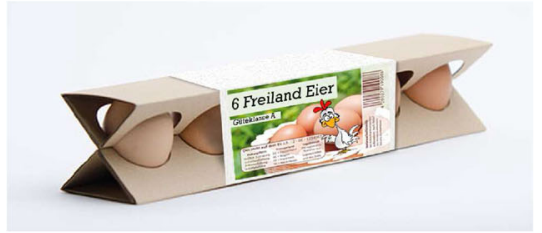

Price: 3.19 Euro

Raising: free-range

Quality Grade: A

Country of Origin: Austria

Shelf Life: 2 weeks

Quantity: 6 eggs

"Emotional" stimulus

\section{Price: 3.10 Euro}

Raising: free-range, with additional information on raising of chicken

Quality Grade: A/extra large

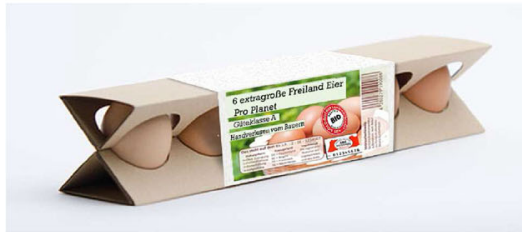

Country of Origin: Austria, of guaranteed origin

Shelf Life: 2 weeks

Quantity: 6 eggs

Additional information: GM-free, salmonella-free, animal rights tested,

"Cognitive" stimulus

\section{free of toxins, hygiene programme}

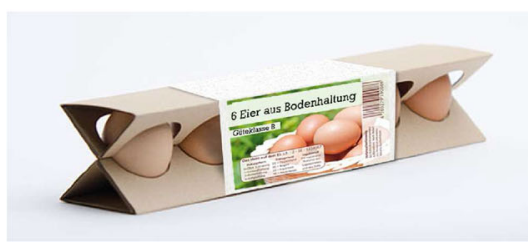

Price: 3.19 Euro

Raising: barn/deep litter

Quality Grade: B

Country of Origin: Austria

Shelf Life: 2 weeks

Quantity: 6 eggs

"Filler" stimulus

Fig. 1 Stimulus material for Austria (in Spain, Country of Origin was indicated as Spain)

in decision making. The time interval of forty seconds used in the present study was based on a pretest indicating that forty seconds are a sufficiently long time interval to get a rough impression of all products and choose one offer, however, not long 
enough to screen the offers in more detail. Results from the pretest show that even in the non-time pressure condition less than ninety seconds are used to decide on a product.

After deciding on a specific product, respondents were requested to state the reasons for their decision in an open-ended question followed by a set of questions on their buying behavior (buying rate, usage rate) with respect to the product category of interest, their attitude to and liking of this product category and a translated version of the decision making style instrument by Scott and Bruce (1995) as shown in the "Appendix". Demographic information was collected at the end of questionnaire.

Stimuli for each heuristic condition consisted of an image of an appropriately designed egg carton of a fictitious brand as well as a short product description, presented in the same manner and design for all products and always incorporating information on price, the raising of chicken, quality grade, country of origin, shelf life and the quantity of eggs in the carton. The product description of the cognitive complex stimulus contained additional information beyond the mentioned points, which was not present for the other stimuli. Figure 1 shows the images presented to subjects as well as the information provided with each stimulus.

Images as well as product descriptions differ only with respect to the characteristics essential for the particular heuristic condition. Generally, all egg cartons were visualized in a novel and innovative shape, except for the stimulus targeted at the recognition heuristic, where a familiar shape was presented. The product targeted at the take-the-best heuristic was offered for a special price, which was prominently displayed on the package for easy retrieval. In the emotional condition, a picture of a cartoon chicken was added to stimulate emotional bonding with the product. On the product package of the cognitive complex condition, additional seals of quality and further information were visualized. The filler product was offered at a lower quality compared to the rest of the stimuli. In order to ensure a professional design of the cartons, all images were created by a graphic designer.

A manipulation check $(n=30)$ was conducted to test the stimulus material with regard to overall attitudes, pleasantness, stimulus concreteness, informative value and complexity of the stimuli. Cartons with low evaluations with regard to overall attitudes and pleasantness were removed from the set. In addition, also the questionnaire was carefully pre-tested to check for possible problems with statement clarity and respondent understanding of how to complete the task. No problems were detected in this pretest.

We employed well established scales for measurement. For the measurement of decision making styles we used the 25-item scale by Scott and Bruce (1995) as adapted to the German language by Gettinger et al. (2013). For the second experiment, the items were translated into Spanish and a native speaker conducted a backward-translation. Both translations are shown in the "Appendix". All 25 items were measured on a seven-point Likert-type scale.

Attitudes towards the product category of interest were assessed by three semantic differential items (Kempf and Laczniak 2001), while for the assessment of liking we used a seven-point rating scale (Ares and Deliza 2010) reaching from 1 (dislike very much) to 7 (like very much). 


\subsection{Sample composition}

We conducted two identical experiments, one in Vienna, Austria, in May 2014, and the other one in Madrid, Spain, in October 2014. Students and staff from the Faculty of Business, Economics and Statistics of the University of Vienna (Austria) and from the Economics and Business School of the Complutense University of Madrid (Spain) were asked to voluntarily participate in the study as well as spread the questionnaire link among their family and friends in order to get a wider sample.

The Austrian sample consisted of 178 respondents, thereof $63 \%$ females. Participants' age ranged from 13 to 69 years with an average of 28 years. The sample contained $48.9 \%$ persons in education, $33.7 \%$ white-collar workers and employees working in public institutions, $3.9 \%$ blue-collar workers, $5.6 \%$ selfemployed, $0.6 \%$ retirees and $7.3 \%$ unemployed. Participants were recruited for the experiment via two channels. On the one hand, respondents were recruited through social media platforms and e-mail, on the other hand, students participated in exchange for course credits.

An average of 5.57 for product liking can be reported on a seven point scale. The 81 respondents who were randomly assigned to the time-pressure condition, spent on average $36.57 \mathrm{~s}$ on the respective page. In contrast, the 97 respondents in the non-time pressure condition spent on average $75.05 \mathrm{~s}$. With respect to the frequency of product purchase, almost $40 \%$ of respondents purchase eggs a number of times per month. Approximately $30 \%$ specified a purchasing frequency of once a week, followed by $12 \%$ of respondents, who purchase the respective product only once a month. Almost $8 \%$ of participants buy egg cartons less than once a month, $4.5 \%$ several times a week and $3.4 \%$ never. Respondents were also asked to indicate the frequency of their product consumption. The majority of participants (36\%) consume eggs several times a week, followed by $28.1 \%$, who indicated to consume eggs once a week. $24.2 \%$ of participants specified a consumption frequency of a number of times per month.

A total of 142 Spanish respondents participated in the replication of the experiment, consisting of $51 \%$ females and $49 \%$ males. With an average of 27 years, respondents' age ranged from 19 to 71 . In terms of occupation, the majority of the respondents were in education $(73.9 \%$ ), followed by $16.6 \%$ whitecollar workers and employees working in public institutions, $2.6 \%$ blue-collar workers, $2.6 \%$ self-employed respondents, $1.3 \%$ retirees and a minority of unemployed participants. Product liking, with an average of 5.83, is very similar to Austria.

The Spanish sample, similarly to the Austrian one, spent on average more time on the respective questionnaire in the condition without time pressure. Overall, 84 respondents were assigned to the condition without time pressure and 73 with time pressure. The majority of the Spanish respondents (46.5\%) purchase eggs once a week, $28.03 \%$ a few times per month, and approximately $10 \%$ once a month. Frequent egg purchasers (daily, a few times per week) and respondents who purchase eggs less than once a month or never constitute a minority. When comparing the egg consumption of Spain with Austria, it can be argued that Spanish respondents consume (and purchase) more eggs. Almost $60 \%$ of the Spanish 
respondents consume eggs several times per week, approximately $20 \%$ once a week and $15 \%$ a few times per month. A $\chi^{2}$ test indicates that differences in egg consumption between the two countries are significant at $p<0.1 \%$, and differences in purchase behavior are significant at $p<5 \%$.

Since most groups except students and white-collar workers were only weakly represented in the sample, we decided to drop those groups altogether to obtain a more homogeneous sample. Furthermore, we dropped respondents who obviously were just clicking through the online questionnaire and thus we eliminated all respondents who had answered 7 to all four questions about attitude, and to more than ten questions of the decision style questionnaire. The resulting reduced samples were used for all further analyses. For the experiments in Austria, the reduced sample consisted of 143 respondents, $92(64.3 \%)$ of which were female and 51 $(35.7 \%)$ were male. The final sample from the experiment in Spain consisted of 128 respondents, out of which $66(51.6 \%)$ were female and $42(48.4 \%)$ were male.

\section{Results}

\subsection{Scales}

Since we had to translate items for the decision making styles into German and Spanish, respectively, we first performed an exploratory factor analysis to analyze the factor structure of responses. Because decision making styles are not necessarily orthogonal, we used an oblimin rotation for this analysis.

Table 1 shows the factor loadings for data obtained in Vienna. For clarity, this table not only shows the factor loadings exceeding the usual threshold of 0.4 , but in parentheses also factor loadings exceeding 0.3. Most items load as expected, only two items had higher loadings on other factors than the expected ones. Item S5 "When making decisions, I do what seems natural at the moment" loads onto the factor associated with the intuitive style with a factor loading of 0.45 (above the 0.4 threshold), rather than the spontaneous style. However, it should be noted that also in the original paper by Scott and Bruce (1995), the spontaneous style was added at a later stage, and the item in question is somewhat ambiguous. Item D5 loaded on the factor associated with the rational style with a factor loading of 0.35 , which is below the threshold. Its loading in the factor associated with the dependent style was not much lower at 0.28 .

Similar results were obtained for the data from Madrid (Table 2). Again, item S5 does not exhibit a high loading on the factor corresponding to the spontaneous style, but loads (at 0.37 ) onto the factor corresponding to the intuitive style. Item I4 did not load on any factor with a loading of more than 0.3 , its highest factor loading was still on the factor associated with the intuitive style at 0.25 . Given that these deviations from the theoretical factor structure are quite small, we decided to retain the original scale of Scott and Bruce (1995). 
Table 1 Factor loadings of decision style items-Vienna

\begin{tabular}{|c|c|c|c|c|c|}
\hline Item & Factor 1 & Factor 2 & Factor 3 & Factor 4 & Factor 5 \\
\hline A1 & 0.71 & & & & \\
\hline A2 & 0.91 & & & & \\
\hline A3 & 0.88 & & & & \\
\hline A4 & 0.82 & & & & \\
\hline A5 & 0.77 & & & & \\
\hline D1 & & 0.75 & & & \\
\hline D2 & & 0.61 & & & \\
\hline D3 & & 0.88 & & & \\
\hline D4 & & 0.80 & & & \\
\hline D5 & & & & $(0.35)$ & \\
\hline I1 & & & 0.60 & & \\
\hline I2 & & & 0.61 & & \\
\hline I3 & & & (0.39) & $(0.36)$ & \\
\hline I4 & & & 0.63 & & \\
\hline I5 & & & 0.85 & & \\
\hline R1 & & & & 0.54 & $(-0.31)$ \\
\hline R2 & & & & $(0.38)$ & \\
\hline R3 & & & & 0.69 & \\
\hline $\mathrm{R} 4$ & & & & 0.46 & $(-0.35)$ \\
\hline R5 & & & & 0.58 & \\
\hline S1 & & & & & 0.71 \\
\hline S2 & & & & & 0.83 \\
\hline S3 & & & & & 0.77 \\
\hline S4 & & & & & 0.55 \\
\hline S5 & & & 0.45 & & $(0.34)$ \\
\hline
\end{tabular}

\subsection{Descriptive results}

The distribution of scores in the decision making styles for the subjects in the two experiments is shown in Fig. 2. The pattern of decision making styles is quite similar across the two experiments. Subjects on average score rather high with respect to the rational style, and low with respect to the avoiding and spontaneous styles. In both experiments, the avoiding style also shows the highest variance.

Table 3 presents an overview of product choices in the entire sample.

Figure 3 shows the distribution of choices across the two experimental conditions. In both experiments, applying time pressure led to a smaller number of subjects choosing the "cognitive" product, and an increase in the share of the products fitting the take-the-best and recognition heuristics. Under both experimental conditions, subjects in Vienna selected the "cognitive" and "recognition" product more often than subjects in Madrid, and the "take-the-best" product less often. The emotional and filler products were chosen only rarely in both experiments, and the filler product only under time pressure. 
Table 2 Factor loadings of decision style items-Madrid

\begin{tabular}{llllll}
\hline Item & Factor 1 & Factor 2 & Factor 3 & Factor 4 & Factor 5 \\
\hline A1 & 0.62 & & & & \\
A2 & 0.81 & & & & \\
A3 & 0.80 & & & & \\
A4 & 0.69 & & & & \\
A5 & 0.77 & & & & \\
D1 & & 0.56 & & & \\
D2 & & 0.55 & & & \\
D3 & & 0.75 & & & \\
D4 & & 0.85 & & & \\
D5 & & 0.50 & & & \\
I1 & & & 0.81 & & \\
I2 & & & 0.89 & & \\
I3 & & & 0.35 & & \\
I4 & & & & & \\
I5 & & & 0.66 & & \\
R1 & & & & 0.52 & \\
R2 & & & & 0.79 & \\
R3 & & & & 0.49 & \\
R4 & & & & 0.50 & \\
R5 & & & & 0.64 & \\
S1 & & & & & \\
S2 & & & & & \\
S3 & & & & & \\
S4 & & & & & \\
S5 & & & & & \\
\hline
\end{tabular}

Decision styles - Madrid

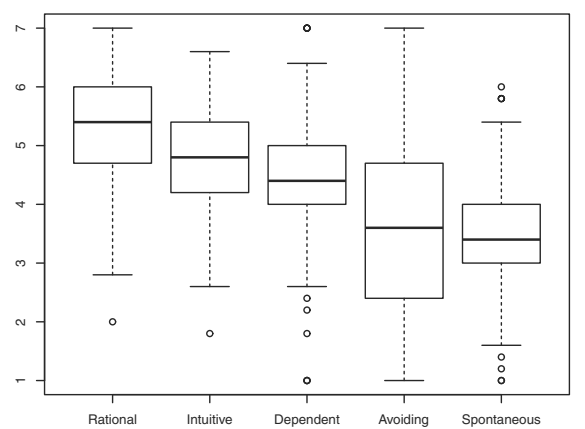

Decision styles - Vienna

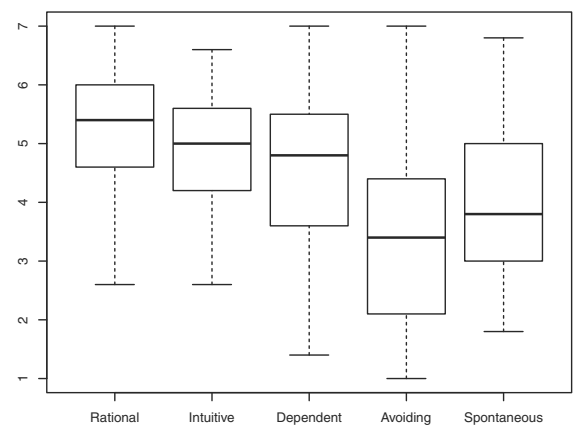

Fig. 2 Distribution of decision making style scores for subjects in Madrid (left) and Vienna (right) 
Table 3 Product choices across the two experiments

\begin{tabular}{lllllll}
\hline & Emotional & Cognitive & Filler & Take the best & Recognition & Sum \\
\hline Vienna & 3 & 72 & 2 & 40 & 26 & 143 \\
Vienna $\%$ & $2.10 \%$ & $50.35 \%$ & $1.40 \%$ & $27.97 \%$ & $18.18 \%$ & 128 \\
Madrid & 5 & 50 & 2 & 56 & 15 & $11.72 \%$ \\
Madrid \% & $3.91 \%$ & $39.06 \%$ & $1.56 \%$ & $43.75 \%$ & \\
\hline
\end{tabular}

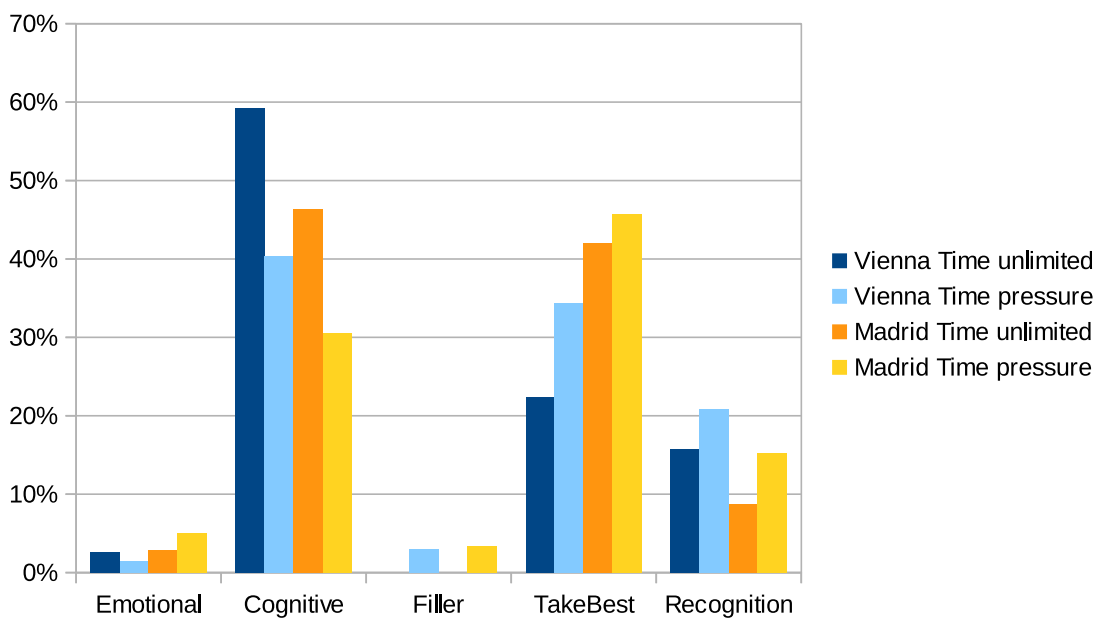

Fig. 3 Distribution of choices among products for both experiments and treatments

\subsection{Multiple correspondence analysis}

In order to obtain a first impression of the relationships between time pressure, decision making styles and the use of different heuristics, we performed a Multiple Correspondence Analysis (MCA). This method is aimed specifically at quantifying categorical data (Greenacre 2007), that is, assigning numerical scale values to the response categories of several discrete variables, with certain optimal properties. These scale values have been shown to have interesting geometric properties and provide maps of the relationships between variables. The ultimate aim of MCA is to produce a map of those relations in a similar way to principal components analysis, in that the total variance of the variables is defined and then this total is decomposed optimally along so-called "principal axes". The total variance in MCA is measured by the so-called inertia, which is simply the usual Pearson chi-square statistic calculated on the cross-tabulation, divided by the total sample size $n$. It is this inertia which measures the degree of difference between the values of the variables that we are trying to represent optimally in the eventual map. For mapping purposes, it is usually hoped that a large percentage of the total inertia is accounted for by the first 
two principal axes, thereby allowing the relations to be visualized in two dimensions.

The application of MCA on our data showed that the percentage of total inertia explained by the first two dimensions is equal to $53.39 \%$. As $41.80 \%$ is due to the first axis, this is the more explicative dimension. A visualization of the results is presented in Fig. 4. The first axis reveals an opposition between the two cities where the experiment was undertaken (Madrid and Vienna) while the second axis, which explains a lot less variability (11.60\% of the total inertia), specifies the time pressure of the experiment. Therefore the horizontal direction in the map separates respondents on the basis of the city. The vertical dimension differentiates respondents on the basis of time constraint.

The proximity between levels of different nominal variables means that these levels tend to appear together in the observations. Different colors have been used for each of the variables to facilitate readability. So the top-right quadrant of the plot clearly shows that the categories Time Pressure, White collar, Recognition and Spontaneous are associated. In the case of the same nominal variable the proximity between levels means that the groups of observations associated with these two levels are themselves similar, but also that a variable discriminates better to the extent that its category points are further apart. Proceeding clockwise, Vienna, Female, Cognitive and Avoiding and Dependant are associated. Time unlimited and In education are associated. Finally there seems also to be a relation between Madrid, Male, Take-the-best, Emotional and Filler and Rational.

The MCA clearly indicates that the two cities are a major factor in explaining the differences of outcomes. We therefore decided not to pool data from the two experiments, but analyze them separately. All following analyses will thus be performed separately for the two data sets.

\section{Symmetric variable plot}

(axes F1 and F2: 53,39\%)

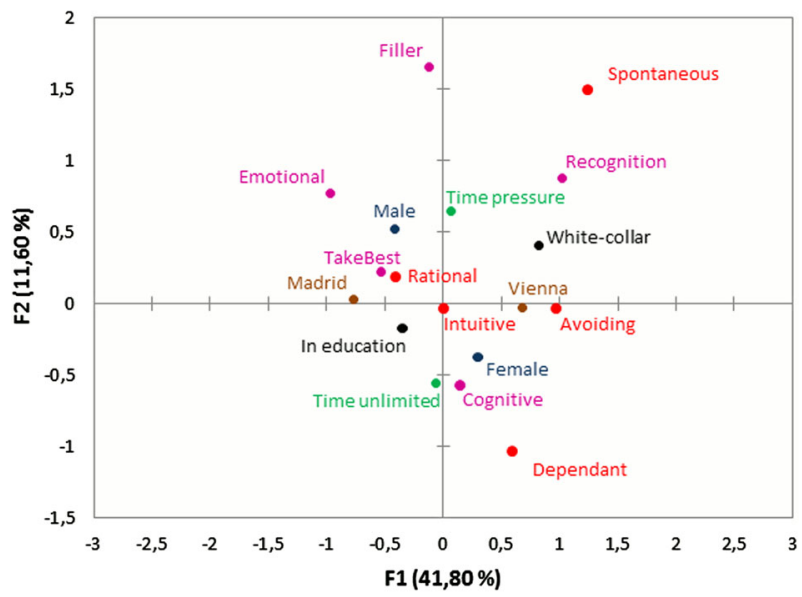

Fig. 4 Multiple correspondence analysis 


\subsection{Regression analysis}

Given that the emotional and filler products were chosen so rarely, we decided not to include them in the following analyses. In order to analyze our research questions, we estimated four nested multinomial regression models for each experiment. The first model (M1) contained only the control variables Gender and Age. The second model (M2) added our treatment variable Time pressure. In the third (M3) and fourth (M4) models, we added decision styles and their interaction with the treatment variable, respectively. In all these regressions, the "cognitive" product was used as reference category, so regression coefficients indicate how strongly each factor influences the switch from "cognitive" to the indicated other product. Tables 4 and 5 show the regression results for the two experiments.

For both experiments, model M1 (and mostly also the subsequent models) indicates that the "recognition" product is chosen significantly less often than "cognitive" (the reference category), but that age has a positive impact, although small, on the choice of "recognition", i.e. older respondents tend to choose the product with familiar package more frequently. Moving to model M2, we find a significant treatment effect only in the Vienna experiments, where time pressure causes a significant shift from "cognitive" to the "take-the-best" product. Thus, we find only limited evidence for a positive answer of $R Q 1$, the use of heuristics increases with time pressure only in one of the two experiments.

The effects of decision styles are also very different between the two experiments. There are no significant effects in the Madrid experiments at all in model M3 (which looks at the average across treatment conditions). Adding the interaction terms in model M4 reveals that a high score in the rational decision style leads to a less frequent choice of the "take-the-best" product (and thus a more frequent choice of "cognitive") without time pressure, and this ordering is reversed under time pressure. This corresponds to our expectations as formulated in $R Q 2$. A reverse effect of time pressure can be observed for subjects scoring high in the dependent style.

In contrast, in the Vienna experiments, we mainly find effects of decision styles which are not influenced by time pressure. Surprisingly, subjects who score high on the intuitive style are significantly more likely to choose the "cognitive" product than either of the other two products, and subjects who score high on the rational style choose the "take-the-best" product more often, rather than the "cognitive" product. More in line with our expectations formulated in $R Q 4$, we also find that subjects who score high in the spontaneous style are more likely to choose the "recognition" product instead of the "cognitive" one. In neither data set we find the relationships between avoidant and dependent styles and the recognition product to which $R Q 3$ refers.

Finally, to take into account the differences between choices of the "take-the-best" and "recognition" products, we also estimated multinomial regression models using these products as reference categories. Figures 5 and 6 summarize the significant results of all estimations. Please note that arrows in these figures do not represent influences from one of the products to the other, but indicate that the factor indicated in the text on each arrow causes a significant shift in choices from one product to another.

For the Vienna data, there are no significant effects causing a shift between "take-the-best" and "recognition" products. In the Madrid data, time pressure in 
Table 4 Multinomial regression results-Madrid

\begin{tabular}{|c|c|c|c|c|}
\hline & M1 & M2 & M3 & M4 \\
\hline Recognition & $-3.1390 * * *$ & $-3.4013 * * *$ & -4.4565 & $-10.7695^{*}$ \\
\hline TakeBest & -0.4142 & -0.5472 & -2.1716 & -0.5302 \\
\hline Recognition:male & 0.1990 & 0.1184 & 0.1705 & 0.3137 \\
\hline TakeBest:male & -0.0006 & -0.0384 & 0.1891 & 0.3068 \\
\hline Recognition:age & $0.0669 *$ & $0.0632 *$ & $0.0639 *$ & $0.0667^{\circ}$ \\
\hline TakeBest:age & 0.0210 & 0.0189 & 0.0213 & 0.0205 \\
\hline Recognition:time pressure & & 0.8526 & 0.7391 & $12.1754^{\circ}$ \\
\hline TakeBest:time pressure & & 0.4828 & 0.3790 & -4.0669 \\
\hline Recognition:rational & & & -0.0218 & 0.2254 \\
\hline TakeBest:rational & & & -0.3090 & $-0.9119 *$ \\
\hline Recognition:intuitive & & & 0.1382 & 0.5046 \\
\hline TakeBest:intuitive & & & 0.3559 & 0.4713 \\
\hline Recognition:dependent & & & 0.0541 & 0.3788 \\
\hline TakeBest:dependent & & & 0.2049 & $0.5238^{\circ}$ \\
\hline Recognition:avoiding & & & -0.3076 & 0.0238 \\
\hline TakeBest:avoiding & & & 0.0762 & 0.1291 \\
\hline Recognition:spontaneous & & & 0.3770 & 0.4701 \\
\hline TakeBest:spontaneous & & & 0.0682 & -0.1252 \\
\hline Recognition:time pressure:rational & & & & -0.5879 \\
\hline TakeBest:time pressure:rational & & & & $1.1249^{\circ}$ \\
\hline Recognition:time pressure:intuitive & & & & -0.5589 \\
\hline TakeBest:time pressure:intuitive & & & & 0.0109 \\
\hline Recognition:time pressure:dependent & & & & -0.5546 \\
\hline TakeBest:time pressure:dependent & & & & $-0.7891^{\circ}$ \\
\hline Recognition:time pressure:avoiding & & & & -0.6852 \\
\hline TakeBest:time pressure:avoiding & & & & -0.0081 \\
\hline Recognition:time pressure:spontaneous & & & & -0.2664 \\
\hline TakeBest:time pressure:spontaneous & & & & 0.5469 \\
\hline McFadden R2 & 0.024 & 0.034 & 0.073 & 0.132 \\
\hline Likelihood ratio & 5.610 & 8.100 & 17.365 & 31.298 \\
\hline
\end{tabular}

$* * * p<0.1 \%, * * p<1 \%, * p<5 \%,{ }^{\circ} p<10 \%$

general causes a shift from "take-the-best" to "recognition", which is partly offset for subjects who score high on the rational style.

\section{Discussion and conclusions}

Our results have provided some evidence with respect to the research questions formulated in Sect. 2, which we summarize below: 
Table 5 Multinomial regression-Vienna

\begin{tabular}{|c|c|c|c|c|}
\hline & M1 & M2 & M3 & M4 \\
\hline Recognition & $-2.2544 * *$ & $-2.7231 * * *$ & -3.5248 & $-6.3776^{\circ}$ \\
\hline TakeBest & -0.7580 & $-1.3210^{\circ}$ & -1.8657 & -2.7020 \\
\hline Recognition:male & -0.3963 & -0.3333 & -0.6289 & -0.7594 \\
\hline TakeBest:male & -0.2356 & -0.1646 & -0.5278 & -0.6986 \\
\hline Recognition:age & $0.0483^{*}$ & $0.0523^{*}$ & $0.0500^{\circ}$ & $0.0501^{\circ}$ \\
\hline TakeBest:age & 0.0094 & 0.0149 & 0.0200 & 0.0188 \\
\hline Recognition:time pressure & & 0.7366 & 0.6910 & 5.8068 \\
\hline TakeBest:time pressure & & $0.8262 *$ & $0.8799 *$ & 1.7516 \\
\hline Recognition:rational & & & 0.3391 & 0.5043 \\
\hline TakeBest:rational & & & $0.5393^{\circ}$ & $0.8639^{\circ}$ \\
\hline Recognition:intuitive & & & $-0.6778^{*}$ & $-0.9670^{\circ}$ \\
\hline TakeBest:intuitive & & & $-0.8500 * *$ & $-1.2534 * *$ \\
\hline Recognition:dependent & & & -0.2027 & 0.1263 \\
\hline TakeBest:dependent & & & -0.0608 & 0.2728 \\
\hline Recognition:avoiding & & & 0.2202 & 0.1501 \\
\hline TakeBest:avoiding & & & 0.0370 & -0.3431 \\
\hline Recognition:spontaneous & & & $0.6654 *$ & $1.1755^{*}$ \\
\hline TakeBest:spontaneous & & & $0.4794^{\circ}$ & 0.6453 \\
\hline Recognition:time pressure:rational & & & & -0.2977 \\
\hline TakeBest:time pressure:rational & & & & -0.4428 \\
\hline Recognition:time pressure:intuitive & & & & 0.4708 \\
\hline TakeBest:time pressure:intuitive & & & & 0.8789 \\
\hline Recognition:time pressure:dependent & & & & -0.6667 \\
\hline TakeBest:time pressure:dependent & & & & -0.6844 \\
\hline Recognition:time pressure:avoiding & & & & 0.2172 \\
\hline TakeBest:time pressure:avoiding & & & & $0.6702^{\circ}$ \\
\hline Recognition:time pressure:spontaneous & & & & -0.8496 \\
\hline TakeBest:time pressure:spontaneous & & & & -0.4200 \\
\hline McFadden R2 & 0.017 & 0.035 & 0.101 & 0.139 \\
\hline Likelihood ratio & 4.678 & 9.785 & $28.119^{*}$ & $38.887 *$ \\
\hline
\end{tabular}

$* * * p<0.1 \%, * * p<1 \%, * p<5 \%,{ }^{\circ} p<10 \%$

RQ1 Impact of time pressure on heuristics: We find some evidence for an increase in take the best in one experiment (Vienna), but not in the other experiment (Madrid).

RQ2 Rational decision makers switch to take the best under time pressure: Weak effect in the Madrid experiments, in the Vienna experiments, rational decision makers tend to use take the best independent of time pressure.

RQ3 Positive relationship between avoidant/dependent styles and recognition: No evidence. 


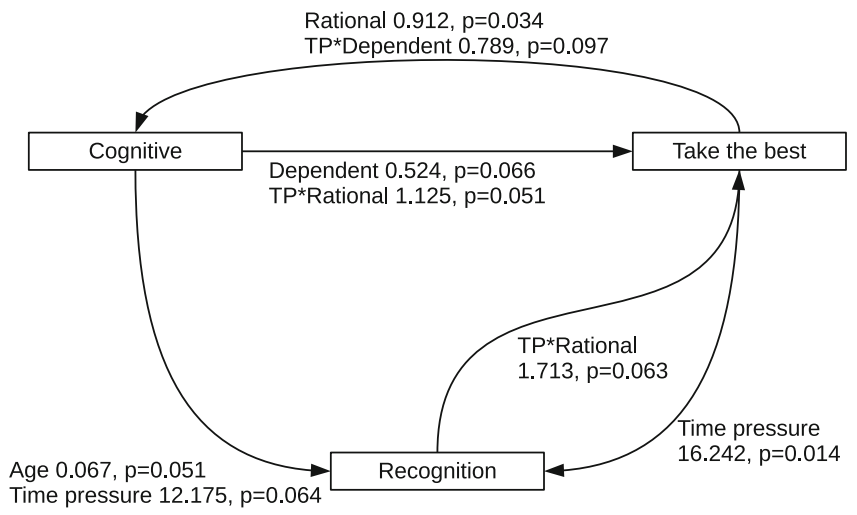

Fig. 5 Summary of regression results-Madrid

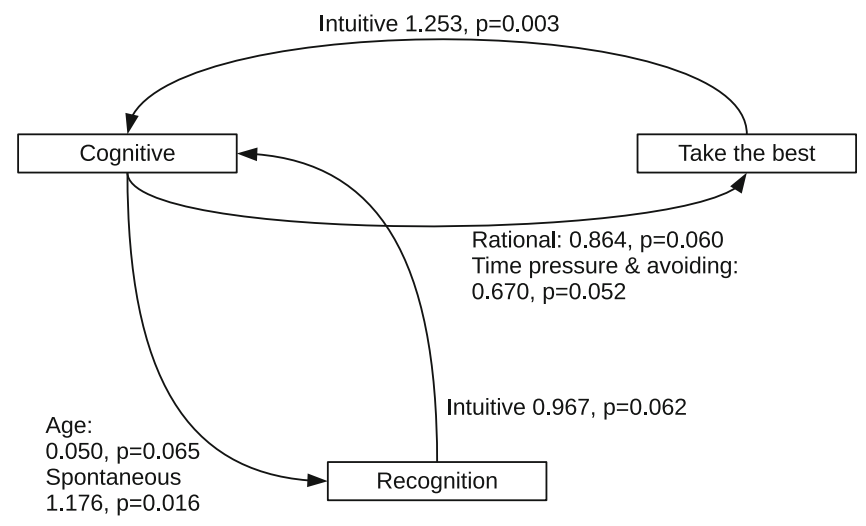

Fig. 6 Summary of regression results_-Vienna

RQ4 Positive relationship between spontaneous style and recognition: Significant relationship in the Vienna experiment, no relationship in the Madrid experiment.

Apart from these limited answers to our research questions, our empirical study has led to some additional insights on the role of decision making styles and heuristics in the cross-cultural context of the two experiments we performed. Although the distribution of decision making styles is remarkably similar across the two experiments, there are some differences in the factor structure of the instrument, which seem to indicate that the questionnaire of Scott and Bruce (1995) might to some extent be dependent on culture. In particular, the spontaneous style seems to be less robust against cultural variations than the other dimensions. Not only the factor analysis shown in Tables 1 and 2 shows slightly different assignments of the items related to the spontaneous style to factors. The spontaneous style is also the 
only style for which a t-test reveals significant differences in scores between Vienna and Madrid (at $p<0.1 \%$ ), for all the other styles differences are insignificant.

We also find even stronger differences in the choice patterns among the two experiments. This seems to indicate that product choices in the two cultures could be influenced by different factors in addition to decision making styles. Our data indicates that subjects in Madrid on average purchase and consume eggs more frequently than in Vienna. Although it might be possible to relate these differences in consumption patterns to differences in the use of heuristics, both the direction of the effect and causality remain ambiguous. On the one hand, use of more, or different, heuristics could lead to different consumption patterns. On the other hand, more frequent, and thus more routine purchases could influence the use of heuristics in either direction: The decision could become more "automatic", with an increased reliance on heuristics, or consumers could become more involved and use less heuristics. The more frequent choice of the "take-the-best" product in Madrid could be an indicator of more routinized purchase behavior.

Our results also allow us to draw some managerial implications for product design and marketing. In both experiments, we find that time pressure leads to a considerable decline in choosing the cognitively complex product. In an increasingly hectic world, where consumers have less time for their product decisions, avoiding cognitive complexity and making consumers' choice as simple as possible seems to be a necessity. As our results have shown, even consumers scoring high in the rational dimension do not necessarily prefer the cognitively complex product. Comparing choices of the take-the-best and recognition products, we can also observe that familiarity is no guarantee for sales, but that providing consumers one particular reason could be a good strategy (as long as this provides exactly the one cue on which consumers focus in a take-the-best strategy).

Of course our study has several limitations. One of its major limitations is that we were not able to observe decision processes directly, but can only infer them from the products chosen. Furthermore, as we have already mentioned, the cross-cultural validity of the instrument by Scott and Bruce (1995) should be examined more thoroughly, leading perhaps to culture-specific variants of the instrument. Our study was also limited to one specific product category of low involvement daily choice products. The impact of a rational decision style could be much stronger for more important purchase decisions. While the relationship between products and underlying decision strategies in our study is quite plausible, it also needs to be studied further and more general methods are needed to identify whether a particular decision was indeed made by using a specific heuristic. Such improved designs could help to obtain more insights into the relationship of decision making styles and the use of heuristics.

Acknowledgments Open access funding provided by University of Vienna.

Open Access This article is distributed under the terms of the Creative Commons Attribution 4.0 International License (http://creativecommons.org/licenses/by/4.0/), which permits unrestricted use, distribution, and reproduction in any medium, provided you give appropriate credit to the original author(s) and the source, provide a link to the Creative Commons license, and indicate if changes were made. 


\section{Appendix: Translated items from Scott and Bruce (1995)}

\begin{tabular}{ll}
\hline Item & German \\
\hline R1 & Ich plane wichtige Entscheidungen sorgfältig \\
I1 & $\begin{array}{c}\text { Bei einer Entscheidungsfindung verlasse ich } \\
\text { mich auf meinem Instinkt }\end{array}$ \\
D1 $\quad \begin{array}{l}\text { Bei wichtigen Entscheidungen benötige ich oft } \\
\text { Unterstützung von anderen Personen }\end{array}$ \\
A1 $\quad \begin{array}{l}\text { Ich vermeide wichtige Entscheidungen zu } \\
\text { treffen, bis ein Druck zur } \\
\text { Entscheidungsfindung besteht }\end{array}$
\end{tabular}

S1 Generell treffe ich oft schnelle Entscheidungen

R2 Ich kontrolliere Informationsquellen zweimal, um sicher zu sein, dass ich für meine Entscheidungen die richtigen Faktoren berücksichtige

I2 Wenn ich Entscheidungen treffe, verlasse ich mich auf meine Intuition

D2 Ich mache selten wichtige Entscheidungen ohne andere Personen zu befragen

A2 Wenn möglich verschiebe ich Entscheidungen

S2 Ich treffe meine Entscheidungen oft spontan

R3 Ich treffe Entscheidungen auf eine logische und systematische Art und Weise

I3 Generell treffe ich Entscheidungen, die sich richtig anfühlen

D3 Mit der Unterstützung anderer Menschen, fällt es mir leichter, Entscheidungen zu treffen

A3 Ich schiebe oft wichtige Entscheidungen auf

S3 Ich treffe schnelle Entscheidungen

R4 Meine Entscheidungsfindung verlangt sorgsames Nachdenken

I4 Wenn ich Entscheidungen treffe, ist es für mich wichtiger, dass sich die Entscheidungen richtig anfühlen, als dass ich einen rationalen Grund dafür habe

D4 Ich berufe mich auf den Rat anderer Menschen, wenn ich wichtige Entscheidungen treffe

A4 Generell treffe ich wichtige Entscheidungen in der letzten Minute

S4 Ich treffe Entscheidungen oft auf eine gefühlsbetone Art

R5 Wenn ich Entscheidungen treffe, berücksichtige ich verschiedene Optionen für ein bestimmtes Ziel
Spanish

Planifico mis decisiones importantes con cuidado

En la toma de deciciones me fío de mis instintos

Con frecuencia necesito la ayuda de otras personas cuando tomo decisiones importantes

Evito tomar decisiones importantes hasta que me siento presionado

Generalmente tomo decisiones sin pensarlo mucho

Compruebo dos veces mis fuentes de informacíon para estar seguro de que tengo los datos correctos antes de tomar una decisíon

Cuando tomo decisiones tiendo a fiarme de mi intuición

Raramente tomo decisiones importantes sin consultar otras personas

Pospongo tomar decisiones siempre que puedo

Con frecuencia tomo decisiones sin pensarlo

Tomo decisiones de forma lógica y sistemática

Normalmente tomo decisiones que siento que son correctas

$\mathrm{Si}$ alguien me aconseja me resulta más fácil tomar decisiones importantes

Con frecuencia retraso tomar decisiones importantes

Tomo decisiones muy rápido

Tomar una decisión requiere pensarlo bien

Cuando tomo una decisíon es más importante para mí sentir que la decision es correcta que tener una razon racional para ella

Me dejo aconsejar por otras personas a la hora de tomar decisiones importantes

Normalmente tomo las decisiones importantes en el último momento

Con frecuencia tomo decisiones impulsivas

Para tomar una decisión evalúo varias opciones según un objetivo específico 


\begin{tabular}{lll}
\hline Item & German & Spanish \\
\hline I5 & $\begin{array}{c}\text { Wenn ich Entscheidungen treffe, vertraue ich } \\
\text { auf meine inneren Gefühle und Reaktionen }\end{array}$ & $\begin{array}{c}\text { Para tomar una decisión me fío de mis } \\
\text { sentimientos y reacciones personales }\end{array}$ \\
D5 & $\begin{array}{c}\text { Wenn ich wichtige Entscheidungen treffen } \\
\text { muss, mag ich es, etwas zu haben, das mich in } \\
\text { die richtige Richtung lenkt }\end{array}$ & $\begin{array}{c}\text { Me gusta que alguien me dirija en la dirección } \\
\text { correcta cuando tomo decisiones importantes }\end{array}$ \\
A5 & $\begin{array}{c}\text { Ich schiebe viele Entscheidungen auf, weil } \\
\text { mich das Denken darüber unruhig macht }\end{array}$ & $\begin{array}{c}\text { Retraso tomar decisiones porque pensar sobre } \\
\text { ellas me incomoda/pone nervioso }\end{array}$ \\
S5 & $\begin{array}{c}\text { Wenn ich Entscheidungen treffe, tue ich das, } \\
\text { was mir natürlich in diesem Moment }\end{array}$ & $\begin{array}{c}\text { Cuando tomo decisiones hago lo que me parece } \\
\text { natural en ese momento }\end{array}$ \\
& $\begin{array}{l}\text { erscheint }\end{array}$
\end{tabular}

\section{References}

Ares G, Deliza R (2010) Studying the influence of package shape and color on consumer expectations of milk desserts using word association and conjoint analysis. Food Qual Preference 21(8):930-937

Ayal S, Hochman G (2009) Ignorance or integration: the cognitive processes underlying choice behavior. J Behav Decision Making 22(4):455-474

Borges B, Goldstein DG, Ortmann A, Gigerenzer G (1999) Can ignorance beat the stock market? In: Gigerenzer G, Todd P, ABC Research Group (eds) Simple Heuristics That Make Us Smart, chapter 3. Oxford University Press, New York, pp 59-72

Bröder A (2000) Assessing the empirical validity of the "take-the-best" heuristic as a model of human probabilistic inference. J Exp Psychol Learn Memory Cogn 26(5):1332-1346

Bröder A (2003) Decision making with the "adaptive toolbox": Influence of environmental structure, intelligence, and working memory load. J Exp Psychol Learn Memory Cognition 29(4):611-625

Bröder A, Schiffer S (2006) Stimulus format and working memory in fast and frugal strategy selection. J Behav Decision Making 19:361-380

Crossley CD, Highhouse S (2005) Relation of job search and choice process with subsequent satisfaction. J Econ Psychol 26(2):255-268

Curseu P, Schruijer S (2012) Decision styles and rationality: an analysis of the predictive validity of the general decision-making style inventory. Educ Psychol Meas 72(6):1053-1062

de Bruin WB, Parker AM, Fischhoff B (2007) Individual differences in adult decision-making competence. J Personal Soc Psychol 92(5):938-956

Gettinger J, Kiesling E, Stummer C, Vetschera R (2013) A comparison of representations for discrete multi-criteria decision problems. Decision Support Syst 54:976-985

Gigerenzer G (2001) Decision making: nonrational theories. Int Encyclopedia Soc Behav Sci 5:3304-3309

Gigerenzer G, Goldstein DG (1996) Reasoning the fast and frugal way: models of bounded rationality. Psychol Rev 103(4):650-669

Gigerenzer G, Goldstein DG (2011) The recognition heuristic: a decade of research. Judgm Decision Making 6(1):100-121

Gigerenzer G, Todd PM, Group AR (1999) Simple heuristics that make us smart. Oxford University Press

Glöckner A, Bröder A (2011) Processing of recognition information and additional cues: a model-based analysis of choice, confidence, and response time. Judgm Decision Making 6(1):23-42

Greenacre M (2007) Correspondence Analysis in Practice, 2 edn. Chapman and Hall

Hauser J (2011) A marketing science perspective on recognition-based heuristics (and the fast-and-frugal paradigm). Judgm Decision Making 6(5):396-408

Hauser JR (2014) Consideration-set heuristics. J Bus Res 67(8):1688-1699

Hilbig BE (2008) Individual differences in fast-and-frugal decision making: neuroticism and the recognition heuristic. J Res Personal 42(6):1641-1645 
Hilbig BE (2014) On the role of recognition in consumer choice: a model comparison. Judgm Decision Making 9(1):51-57

Hilbig BE, Erdfelder E, Pohl RF (2012) A matter of time: Antecedents of one-reason decision making based on recognition. Acta Psychologica 141(1):9-16

Hilbig BE, Pohl RF (2008) Recognizing users of the recognition heuristic. Exp Psychol 55(6):394-401

Hilbig BE, Pohl RF, Bröder A (2009) Criterion knowledge: a moderator of using the recognition heuristic? J Behav Decision Making 22(5):510-522

Hoffrage U, Reimer T (2004) Models of bounded rationality: the approach of fast and frugal heuristics. Manag Revue 15(4):437-459

Hogarth RM, Karelaia N (2006) "Take-the-best" and other simple strategies: why and when they work "well” with binary cues. Theory Decision 61(3):205-249

Kempf D, Laczniak R (2001) Advertisings influence on subsequent product trial processing. J Advert 13(3):27-38

Langner T, Krengel M (2013) The mere categorization effect for complex products: the moderating role of expertise and affect. J Bus Res 66(7):924-932

Marewski J, Gaissmaier W, Schooler L, Goldstein D, Gigerenzer G (2010) From recognition to decisions: extending and testing recognition-based models for multialternative inference. Psychon Bull Rev 17(3):287-309

Martignon L, Hoffrage U (2002) Fast, frugal, and fit: simple heuristics for paired comparison. Theory Decision 52(1):29-71

Mesías FJ, Martínez-Carrasco F, Martínez JM, Gaspar P (2011) Functional and organic eggs as an alternative to conventional production: A conjoint analysis of consumers preferences. J Sci Food Agricult 91(3):532-538

Newell BR, Fernandez D (2006) On the binary quality of recognition and the inconsequentiality of further knowledge: two critical tests of the recognition heuristic. J Behav Decision Making 19(4):333-346

Newell BR, Weston NJ, Shanks DR (2003) Empirical tests of a fast-and-frugal heuristic: not everyone takes-the-best. Organ Behav Hum Decis Process 91:82-96

Pachur T, Bröder A, Marewski JN (2008) The recognition heuristic in memory-based inference: is recognition a non-compensatory cue? J Behav Decision Making 21(2):183-210

Pachur T, Hertwig R (2006) On the psychology of the recognition heuristic: retrieval primacy as a key determinant of its use. J Exp Psychol Learn Memory Cogn 32(5):983-1002

Payne JW, Bettman JR, Johnson EJ (1993) The adaptive decision maker. Cambridge University Press

Pohl RF (2006) Empirical tests of the recognition heuristic. J Behav Decision Making 19(3):251-271

Reimer T, Rieskamp J (2007) Fast and Frugal Heuristics. Encyclopedia of Social Psychology. SAGE Publications, Inc. SAGE Publications Inc, Thousand Oaks, CA

Scott SG, Bruce RA (1995) Decision-making style: the development and assessment of a new measure. Educ Psychol Meas 55(5):818-831

Slovic P, Finucane ML, Peters E, MacGregor DG (2007) The affect heuristic. Euro J Oper Res 177(3):1333-1352

Sproles GB, Kendall EL (1986) A methodology for profiling consumers' decision-making styles. J Consum Affairs 20(2):267-279

Thoma V, Williams A (2013) The devil you know: the effect of brand recognition and product ratings on consumer choice. Judgm Decision Making 8(1):34-44 